\title{
BMJ Open Traumatic episodes and mental health effects in young men and women in Rwanda, 17 years after the genocide
}

\author{
Lawrence Rugema, ${ }^{1,2}$ Ingrid Mogren, ${ }^{3}$ Joseph Ntaganira, ${ }^{1}$ Gunilla Krantz ${ }^{2}$
}

To cite: Rugema L, Mogren I, Ntaganira J, et al. Traumatic episodes and mental health effects in young men and women in Rwanda, 17 years after the genocide. BMJ Open 2015;5: 006778 .

doi:10.1136/bmjopen-2014006778

- Prepublication history and additional material is available. To view please visit the journal (http://dx.doi.org/ 10.1136/bmjopen-2014006778).

Received 13 October 2014 Revised 9 April 2015 Accepted 23 April 2015

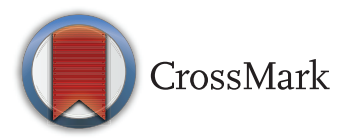

${ }^{1}$ Department of Community Health, School of Public Health, College of Medicine and Health Sciences,

University of Rwanda, Kigali, Rwanda

${ }^{2}$ Department of Public Health and Community Medicine, Institute of Medicine, the Sahlgrenska Academy at University of Gothenburg, Gothenburg, Sweden

${ }^{3}$ Department of Clinical Sciences, Obstetrics and Gynecology, Umeå University, Umea, Sweden

Correspondence to Lawrence Rugema; Irugema@nursph.org

\section{ABSTRACT}

Objectives: To investigate mental health effects associated with exposure to trauma in Rwanda during the 1994 genocide period, and over the lifetime, in Rwandan men and women aged 20-35 years.

Setting: This was a cross-sectional population-based study conducted in the southern province of Rwanda. Data was collected during December 2011 to January 2012.

Participants: A total population of 917 individuals were included, 440 (48\%) men and 477 (52\%) women aged 20-35 years. Number of households for inclusion in each village was selected proportional to the total number of households in each selected village. The response rate was $99.8 \%$. Face-to-face interviewing was done by experienced and trained clinical psychologists, following a structured questionnaire.

Results: Women were slightly less exposed during the genocide period (women $35.4 \%$ and men $37.5 \%$; $\mathrm{p}=0.537$ ), but more women than men were exposed to traumatic episodes over their lifetime (women $83.6 \%$, $n=399$; men $73.4 \%, n=323 ; p<0.001$ ). Current major depressive episodes (MDE) were twice as prevalent in women as in men. Traumatic episodes experienced in the genocide period severely affected men's current mental health status with relative risk (RR) $3.02(95 \%$ $\mathrm{Cl} 1.59$ to 5.37) for MDE past and with RR 2.15 (95\% $\mathrm{Cl} 1.21$ to 3.64 ) for suicidality. Women's mental health was also affected by trauma experienced in the genocide period but to an even higher extent, by similar trauma experienced in the lifetime with RR 1.91 (95\% $\mathrm{Cl} 1.03$ to 3.22$)$ for suicidality and RR $1.90(95 \% \mathrm{Cl}$ 1.34 to 2.42 ) for generalised anxiety disorder, taking spousal physical/sexual violence into consideration.

Conclusions: Depression, post-traumatic stress disorder, anxiety and suicidal attempts are prevalent in Rwanda, with rates twice as high in women compared with men. For women, exposure to physical and sexual abuse was independently associated with all these disorders. Early detection of gender-based violence through homes and community interventions is important.

\section{INTRODUCTION}

Mental health problems contribute to approximately $14 \%$ of the global burden of
Strengths and limitations of this study

This study found that the horrors which took place during the Rwandan genocide in 1994 still strongly contributed to common mental disorders especially in men and in women in Rwanda.

- Traumatic episodes experienced over the lifetime were strongly associated with mental disorders in women, even when controlled for partner violence, indicating that traumatising events also occur in the postgenocide period and influence women's mental health.

- The prevalence of mental disorders was measured by a diagnostic tool, the Mini International Neuropsychiatric Interview instrument, a brief structured interview instrument to diagnose major psychiatric disorders, with properties of good validity and reliability.

- The selected age groups for this study included children as young as 3 years of age at the time of the genocide. This may give rise to underreporting of traumatic exposures especially among the youngest age group.

- Recall bias as well as memory disturbances and repression, may have caused further underreporting.

disease. ${ }^{1}$ Unipolar depression is the second and third leading cause of disability-adjusted life years in women and men, respectively, aged $15-44,{ }^{1}$ and is a major part of lost years of healthy life in low and middle income countries (LMICs). ${ }^{2}{ }^{3}$ Mental disorders further contribute significantly to the overall non-communicable disease (NCD) panorama in LMICs, even more so than other NCDs, such as cancer and cardiovascular diseases. ${ }^{45}$

The most commonly occurring mental disorders affecting young people are depression, anxiety, post-traumatic stress disorder (PTSD) and somatoform disorders. Together, these are often referred to as common mental disorders (CMD) ${ }^{6}$ Suicide attempts are also common among women although there is a wide variation in prevalence in LMICs, and mental disorders or exposures to violence are the main predictors. ${ }^{7}$ Although LMICs suffer 
from high levels of poverty and a high burden of CMDs, this relationship has only been empirically addressed in the last two decades. ${ }^{6}{ }^{8}$ In a review study, it was found that CMDs are strongly associated with lower levels of education and socioeconomic status, as well as with factors such as social exclusion, malnutrition, violence and insecurity, particularly among women. ${ }^{6} 8$

Mental disorders have attracted minimal attention from research and planners of health in LMICs, and this has led to little detection and treatment. ${ }^{9}{ }^{10}$ Roughly $1 \%$ of the total health budget is allocated to mental health services in many poor countries, ${ }^{11}$ and efforts to address mental disorders are unsatisfactory and un-prioritised, due to competing health needs alongside scarcity of well trained personnel for mental healthcare. ${ }^{12}$

Rwanda is a small, low-income country in central Africa with about 10.5 million inhabitants. The majority of the population $(80 \%)$ lives in rural areas and depends on subsistence farming. ${ }^{13}$ At least $63 \%$ of the Rwandan population is under the age of 25 years, ${ }^{14}$ and only $3 \%$ are above 60years. ${ }^{15}$ This younger age group plays a central role in development through their reproductive and productive roles.

The catastrophic acts of the genocide in 1994 gave rise to unprecedented numbers of mental health disorders among children and young adults in Rwanda. ${ }^{16-18}$ In one of our earlier studies, we found that $37 \%$ of the men and $35 \%$ of the women had experienced at least one traumatic episode (mass killings, rape, forced to flee the home) during the genocide period. ${ }^{19}$ In addition, we found that over the lifetime, $73 \%$ of the men and $83 \%$ of the women reported exposure to traumatic episodes, such as being robbed or threatened with a weapon, or having witnessed the unnatural death or imprisonment of a close family member or a friend. ${ }^{19}$ As a consequence, children may also be affected by their parents' suffering from mental disturbances, and an intergenerational effect is being discussed, based on attachment theory and psychosocial stress theory. ${ }^{20}$ Furthermore, throughout life, women are commonly exposed to spousal physical and sexual violence. ${ }^{13} 21$ Other studies conducted at various intervals since the genocide in 1994 show persistent mental health effects. ${ }^{16} 17$ 22-24

In Rwanda, scarcity of mental health professionals ${ }^{15}$ makes availability of treatment options out of reach for many people, and most services available for mental healthcare are concentrated in urban areas. ${ }^{25}$ Currently (2011), the country has five psychiatrists $(0.05 / 100000$ inhabitants) ${ }^{15}$ and two specialised referral hospitals. ${ }^{26}$ District hospitals are commonly staffed with a mental health nurse, while health centres have no trained mental health professionals. ${ }^{27}$

The aim of this study was to investigate the mental health effects of traumatic episodes experienced during the genocide period, that is, 17 years later, as well as associations between lifetime trauma and mental health in Rwandan men and women, aged 20-35 years.
This study is part of a project on violence and traumatic episodes, mental health and barriers to care, The Rwandan Violence, Mental Health and Barriers to Care project (RwVMHBC project).

\section{METHODS}

\section{Population and data collection}

This cross-sectional population-based study took place in the Southern Province of Rwanda, a rural area that includes one urban city, Butare. The sample size calculation was based on a $20 \%$ prevalence of depression in women. ${ }^{17}$ To detect a 1.5-fold risk increase of depression with $80 \%$ probability, the sample size was estimated at 815 people after taking non-responders into consideration. As the prevalence of depression in men is generally lower than in women, ${ }^{16}$ it was decided to increase the sample size to 900 . A total population of 917 individuals was finally included, $440(48 \%)$ men and 477 $(52 \%)$ women aged $20-35 y$ years. The data were collected during the period December 2011 to January 2012.

A two-stage random selection of participants was made using the nation-wide demographic health survey procedure. Rwanda is divided into four provinces, and the Southern Province, with an estimated population of 2 226000 , was chosen and divided into eight districts.

A complete list of all villages and households in the eight districts was made available by the National Institute of Statistics of Rwanda (NISR). Out of the total number of 3512 villages, 35 primary sampling units (villages) were selected. The number of villages in each district was selected proportional to the total number of villages, using Epi-Info to generate random numbers. Finally, the number of households for inclusion in each village was selected proportional to the total number of households in each selected village.

One adult, aged 20-35 years, was selected from the first household closest to the centre of the village. If the first eligible participant was a female, the next participant would be a male. Only one interview was conducted with an eligible individual in each household for ethical and security reasons. If there was no eligible person living in the household, the closest household was approached. The rationale behind this procedure was that living conditions would possibly be similar to that of the originally selected household. If the eligible individual was not at home, the interviewer returned up to three times to interview the selected person. Only two people refused participation in the study, thus the final response rate was $99.8 \%$.

A questionnaire was developed based on previously validated instruments. It contained items on traumatic episodes, physical, sexual and psychological partner violence, physical and mental health and access barriers to care. It was translated into Kinyarwanda and backtranslated by a professional language translator.

A team of 13 clinical psychologists (seven women and six men), experienced in conducting data collection for 
the School of Public Health, University of Rwanda, was trained for 2 days to manage the data collection tools. A 1-day pretesting exercise was carried out, and the questionnaire was revised accordingly. Female participants were interviewed by women, and male participants by men, to minimise information concealment. The data collection was supervised by persons with previous experience of similar studies (LR, the first author, and a team supervisor at the School of Public Health, University of Rwanda).

Each team supervisor was responsible for overseeing the work of the team by identifying the households to be visited, observing interviews, managing questionnaires and reinterviewing a selected number of participants for reliability purposes. Data were entered by four experienced personnel who drew their expertise from entering demographic and health survey data in Rwanda. The supervisor (LR) cross-checked, on a daily basis, the quality of data entered, and if there were any anomalies, these were corrected.

\section{Variables}

\section{Dependent variables}

Mini International Neuropsychiatric Interview (MINI), a brief structured interview instrument to diagnose major psychiatric disorders, was used to estimate prevalence of mental disorders. This instrument was constructed from the Diagnostic and Statistical Manual of Mental Disorders (DSM) IV, V.6.0.0, ${ }^{28}$ and consists of 16 modules. In this study, five modules were used to identify current major depressive episodes (MDE) as periods of depressive mood in the past 2 weeks and past MDEs, defined as earlier periods of depressive mood of at least 2 weeks, current suicidality, current post-traumatic stress disorder, and current generalised anxiety disorder (GAD). The tool has similar validity and reliability properties as the WHO-CIDI instrument, ${ }^{29}$ but has the advantages of taking less time to use even by non-specialised interviewers.

The MINI instrument uses one or more screening questions corresponding with the main criteria of the disorder. If the response was 'no' to all screening questions, the criteria for diagnosis were not met. If the response was 'yes' to any of the screening questions, further questions were asked, and at the end of each module the interviewer indicated whether the diagnostic criteria for a particular disorder were met or not. The MINI questionnaire was translated by a professional language translator, and it was reproduced with the authorisation of the copyright holder (copyright 1994-2010 Sheenan DV \& Lecrubier Y).

\section{Independent variables}

Traumatic episodes were measured by a shortened version of the Harvard Trauma Questionnaire, an instrument that has been used in several other postconflict settings, and validated in different populations and languages. ${ }^{30}$ The authors state that with careful adaptation to a cultural setting, the scale can be used to assess trauma in low and high income settings. ${ }^{32} 33$ Of the 34 items included and directly related to trauma experience, 16 were chosen as appropriate for this study.

The items ask about own experience of traumatic episodes or having witnessed such episodes. Response categories are 'yes' and 'no' with a follow-up question on age at event. Items were treated individually, but for further analyses, a summary index was made for two time periods, during the genocide period and over the lifetime, both dichotomised into having experienced at least one traumatic episode as the exposed, and no such exposure constituted the reference category. The individual items are presented in detail in the online supplementary appendix 1, and prevalence rates are presented in an earlier study. ${ }^{19}$

Sociodemographic and psychosocial variables from the Rwanda DHS 2010, were used with slight adjustments. These were dichotomised for use in multivariable analyses. Age was dichotomised with the age group 3035 years taken as the exposed, and 20-29 years of age as the reference category. Marital status was classified into married or cohabiting, as opposed to being widowed, divorced or single. Number of children was divided into having or not having children, with the latter as the reference category. Educational level was dichotomised with incomplete primary school as the exposed. Ever been to school was categorised into 'yes' and 'no', with 'yes' being the reference category. Employment status was divided into employed and not employed as the exposed. The social support variable was dichotomised into poor social support and good social support. The exposed group lacked social support in all items inquired about.

Household monthly income was dichotomised as having more or less than 17500 RWF (approximately US\$30) available for consumption each month. The assets in the household variable was constructed by summing up eight assets possibly available in the household (radio, television, refrigerator, bicycle, motorcycle, car, mobile phone and computer) and then dichotomised into having or not having at least one of the items.

Occurrence of spousal violence was measured by exposure to physical violence (six items) and/or sexual violence (three items), then used as a combined variable. These items were selected from the women's health and life experiences questionnaire, a validated questionnaire developed by WHO for research on intimate partner violence experience. ${ }^{34}$ Women and men were asked to indicate whether they had ever been exposed to any of the violent acts from their current or earlier husband/ partner.

\section{Statistical methods}

The prevalence of mental disorders and exposure to traumatic episodes in the lifetime, and during the genocide period, were calculated and $\mathrm{p}$ values were given for the difference between men and women using Pearson's $\chi^{2}$ test and Fischer's exact test. Simple associations between traumatic episodes during the genocide period 
and over the lifetime, and mental disorders (major depression current and past, suicidality, PTSD and GAD were calculated by use of relative risk (RR) with their 95\% CI. Multivariable logistic regression analyses were conducted to control for age and to investigate possible additional covariates. RR was approximated from OR, as mental disorders were rather common in the entire study population $(>10 \%)$ to avoid overestimating the risk of mental disorders using formula $\mathrm{RR}=\mathrm{OR} /(1-\mathrm{Po})$ $+(\mathrm{Po} \times \mathrm{OR}){ }^{35}$

For women, variables entered into the analyses were assets in the household, spousal physical/sexual violence and social support (in analyses of GAD only), as these were statistically significantly associated with mental disorders in the simple analyses. As spousal violence was not included in the Harvard Trauma Scale, it was decided to add it to the analysis as it displayed strong associations with all mental disorders under study in another study within the RwVMHBC project. ${ }^{21}$ For men, only assets in the household proved statistically significant in the simple analyses and subsequently controlled for. PTSD was excluded from further analyses as its association with traumatic episodes was neither prominent for women nor for men.

The software SPSS V.19 (SPSS V.19.0; IBM SPSS Inc) was used for all statistical calculations.

\section{Ethical considerations}

Respondents were informed orally and in writing about the possibility of their withdrawing from the study at any stage. Participants were further informed that anonymity and confidentiality would be kept at all stages of the research project. The structured interview following the questionnaire was initiated after a written informed consent was granted by the respondent. All interviews were conducted in complete privacy, either outside the house or inside, or in a nearby location, depending on the choice of the study participant. Personal identity information noted in the questionnaires (village, cluster) was not entered into the data analysis tool. If any participant expressed the need for further treatment and support due to the sensitive matters being dealt with, he or she was referred to a nearby health centre accompanied by a clinical psychologist, that is, one of the interviewers. However, no such cases occurred.

\section{RESULTS}

\section{Respondent's characteristics}

Of the participants (440 men and 477 women), the majority was poor, few obtained secondary or university education (women 17\%, men 13.3\%), few were employed, and the household income was low (table 1).

The assets in the household variable, used as a proxy for poverty, indicated that women, to a higher extent than men, did not have access to any of the assets (women 30.6\%, $\mathrm{n}=146$ men 26.6\%, $\mathrm{n}=117$ ), and $\mathrm{a}$ majority $(89.2 \%)$ of the population possessed only two of the assets inquired about.

Women, to a higher extent than men, were exposed to traumatic episodes over the lifetime (women 83.6\%, $\mathrm{n}=399$; men $73.4 \%, \mathrm{n}=323 ; \mathrm{p}<0.001$ ), but slightly less exposed during the genocide period (women $35.4 \%$ and men $37.5 \% ; \mathrm{p}=0.537$ ) (table 1 ). The youngest age group, 3-5 years of age in the genocide period, were least exposed to traumatic episodes in this time period.

\section{Exposure to mental disorders}

The prevalence of mental disorders was considerably higher in women than men. GAD, was the most prevalent condition in both women and men (table 2). The prevalence of current MDE, that is, in the past 2 weeks, was more than twice as high for women than men (women 26.5\% and men 12.1\%), and past MDE almost three times higher in women than men (women $23.3 \%$ and men $8.4 \%$ ) (table 2).

The same pattern of gender difference was observed for suicidality and PTSD. To a limited extent, there was an overlap in disease patterns, as a number of women and men reported suffering from more than one of the CMDs under study (table 2).

\section{Simple and multivariable associations between traumatic episodes and mental disorders}

A somewhat different pattern in simple associations between episodes of trauma and mental disorders was found for women and men (table 3). Women seemed more mentally affected by traumatic episodes over the lifetime, which included present-day episodes, with statistically significant RR for current MDE (RR 1.70; 95\% CI 1.04 to 2.57 ) and suicidality (RR $1.97 ; 95 \%$ CI 1.12 to 3.08). Traumatic episodes experienced during the genocide period contributed to suicidality with RR 1.49 ; $95 \%$ CI 1.07 to 3.23 ) and to RR 1.55 ; $95 \%$ CI 1.04 to 2.22) for PTSD in women (table 3).

For men, however, traumatic episodes experienced during the genocide period were most influential in relation to mental disorders, as statistically significant RR were found for all mental disorders investigated, apart from PTSD, with the highest RR for past MDE (RR 2.04; 95\% CI 1.42 to 2.60 ), suicidality (RR 2.01; 95\% CI 1.13 to 3.38 ) and current MDE (RR 1.86; 95\% CI 1.13 to 2.93). Traumatic episodes experienced over the lifetime were statistically associated with current MDE and GAD (table 3).

Multivariable analyses were conducted to investigate associations between traumatic episodes and mental disorders, taking other possible covariates into account and adjusting for age (table 4 ).

For women, traumatic episodes experienced in the lifetime constituted a strong risk factor for current MDE (RR 1.74; 95\% CI 1.04 to 2.65) (model 1; table 4). However, this risk factor was no longer statistically significant when spousal physical/sexual violence was added (model 2; table 4). Furthermore, traumatic episodes 
Table 1 Sociodemographic and psychosocial factors of the study population with $p$ values for difference between women and men

\begin{tabular}{|c|c|c|c|c|c|c|c|}
\hline \multirow[b]{2}{*}{ Variables } & \multicolumn{2}{|c|}{$\begin{array}{l}\text { Total population } \\
(\mathrm{N}=917)\end{array}$} & \multicolumn{2}{|c|}{ Men $(\mathrm{N}=440)$} & \multicolumn{2}{|c|}{$\begin{array}{l}\text { Women } \\
(\mathrm{N}=477)\end{array}$} & \multirow[b]{2}{*}{ p Value } \\
\hline & n & Per cent & $\mathrm{n}$ & Per cent & $\mathrm{n}$ & Per cent & \\
\hline \multicolumn{8}{|l|}{ Age groups, years $(n=908)$} \\
\hline $20-24$ & 275 & 30.3 & 148 & 33.8 & 127 & 27.0 & 0.050 \\
\hline $25-29$ & 300 & 33.0 & 144 & 32.9 & 156 & 33.2 & \\
\hline $30-35$ & 333 & 36.7 & 146 & 33.3 & 187 & 39.8 & \\
\hline \multicolumn{8}{|l|}{ Marital status $(n=912)$} \\
\hline Married and cohabiting & 578 & 63 & 236 & 53.8 & 342 & 72.3 & $<0.001$ \\
\hline Widowed and divorced & 35 & 3.8 & 2 & 0.5 & 33 & 7.0 & \\
\hline Single & 299 & 32.8 & 201 & 45.8 & 98 & 20.7 & \\
\hline \multicolumn{8}{|l|}{ Number of children $(n=915)$} \\
\hline No children & 307 & 33.5 & 211 & 48.1 & 96 & 20.2 & $<0.001$ \\
\hline $1-3$ children & 467 & 50.9 & 192 & 43.7 & 275 & 57.8 & \\
\hline$>3$ children & 141 & 15.4 & 36 & 8.2 & 105 & 22.1 & \\
\hline \multicolumn{8}{|l|}{ Level of education $(n=768)$} \\
\hline Secondary school or university level & 117 & 15.2 & 50 & 13.3 & 67 & 17.0 & 0.006 \\
\hline Complete primary or vocational level & 178 & 23.2 & 105 & 28.0 & 73 & 18.6 & \\
\hline Incomplete primary & 473 & 61.6 & 220 & 58.7 & 253 & 64.4 & \\
\hline \multicolumn{8}{|l|}{ Ever been to school $(n=915)$} \\
\hline Yes & 762 & 83.3 & 369 & 84.2 & 393 & 82.4 & 0.479 \\
\hline No & 153 & 16.7 & 69 & 15.8 & 84 & 17.6 & \\
\hline \multicolumn{8}{|l|}{ Employment status ( $n=913$ ) } \\
\hline Full time paid employment & 84 & 9.4 & 55 & 12.5 & 29 & 6.1 & $<0.001$ \\
\hline Irregular or seasonal work & 50 & 5.5 & 33 & 7.5 & 17 & 3.6 & \\
\hline No employment & 779 & 85.3 & 348 & 79.1 & 431 & 90.4 & \\
\hline \multicolumn{8}{|l|}{ Social support ( $n=917$ ) } \\
\hline Good & 592 & 69.6 & 301 & 68.4 & 291 & 60.0 & 0.086 \\
\hline Poor & 258 & 30.4 & 114 & 25.9 & 144 & 30.2 & \\
\hline \multicolumn{8}{|l|}{ Traumatic episodes, genocide period $(n=916)$} \\
\hline Not exposed & 583 & 63.6 & 583 & 62.5 & 308 & 64.7 & 0.537 \\
\hline Exposed & 334 & 36.4 & 334 & 37.5 & 168 & 35.3 & \\
\hline \multicolumn{8}{|l|}{ Traumatic episodes, lifetime prevalence $(n=916)$} \\
\hline Not exposed & 195 & 21.3 & 195 & 26.6 & 78 & 16.4 & $<0.001$ \\
\hline Exposed & 722 & 78.7 & 722 & 73.4 & 399 & 83.6 & \\
\hline \multicolumn{8}{|l|}{ Physical and/or sexual violence, lifetime prevalence } \\
\hline No & 771 & 84.1 & 419 & 95.2 & 352 & 73.8 & $<0.001$ \\
\hline Yes & 146 & 15.9 & 21 & 4.8 & 125 & 26.2 & \\
\hline \multicolumn{8}{|l|}{ Household characteristics } \\
\hline \multicolumn{8}{|l|}{ Household monthly income $(n=883)$} \\
\hline $17500 \mathrm{RF}$ or higher & 189 & 21.4 & 86 & 20.5 & 103 & 22.2 & 0.566 \\
\hline Lower than $17500 \mathrm{RF}$ & 694 & 78.6 & 333 & 79.5 & 361 & 77.8 & \\
\hline \multicolumn{8}{|l|}{ Assets in household, sum measure ( $n=917)$} \\
\hline Improved (at least one of the higher standard items) & 654 & 71.3 & 323 & 73.4 & 331 & 69.4 & 0.189 \\
\hline Poor (none of the higher standard items) & 263 & 28.7 & 117 & 26.6 & 146 & 30.6 & \\
\hline
\end{tabular}

were highly associated with suicidality (RR $1.91 ; 95 \%$ CI 1.03 to 3.22 ) and GAD (RR $1.90,95 \%$ CI 1.34 to 2.42 ) even when other strong factors were entered in the multivariable model (model 2, table 4).

Finally, lack of assets in the household and physical/ sexual partner violence, were strongly associated with a majority of the mental conditions. In addition, poor social support showed a statistically significant association with GAD (table 4).

Traumatic episodes experienced during the genocide period were associated with suicidality (RR 1.84; $95 \%$ CI 1.07 to 2.80 ) and with PTSD (RR 1.84; $95 \%$ CI 1.02 to
2.94) in women when controlled for age and assets in the household (not presented in table 4). Physical/ sexual spousal violence was not included as, at the time of the genocide, the participants were too young to have a stable partner.

For men, traumatic episodes experienced during the genocide period remained a statistically significant predictor of all mental disorders under study, with the highest RR for MDE past (RR 3.02, 95\% CI 1.59 to 5.37) and suicidality (RR 2.15, 95\% CI 1.21 to 3.64) (table 5). However, regression analysis with lifetime episodes of mental disorders, controlling for few assets in the 
Table 2 Prevalence of mental disorders for men and women with $p$ values for difference $(N=917)$

\begin{tabular}{|c|c|c|c|c|c|c|c|}
\hline \multirow[b]{2}{*}{ Mental disorders } & \multicolumn{2}{|c|}{$\begin{array}{l}\text { Total population } \\
(\mathrm{N}=917)\end{array}$} & \multicolumn{2}{|c|}{ Men $(\mathrm{N}=440)$} & \multicolumn{2}{|c|}{ Women $(\mathrm{N}=477)$} & \multirow[b]{2}{*}{ p Value } \\
\hline & n & Per cent & $\bar{n}$ & Per cent & $\bar{n}$ & Per cent & \\
\hline \multicolumn{8}{|c|}{ Major depressive episodes, current $(n=915)$} \\
\hline No & 736 & 80.4 & 386 & 87.9 & 350 & 73.5 & \multirow[t]{2}{*}{$<0.001$} \\
\hline Yes & 179 & 19.6 & 53 & 12.1 & 126 & 26.5 & \\
\hline \multicolumn{8}{|c|}{ Major depressive episodes, past $(n=911)$} \\
\hline No & 764 & 83.9 & 401 & 91.6 & 363 & 76.7 & \multirow[t]{2}{*}{$<0.001$} \\
\hline Yes & 147 & 16.1 & 37 & 8.4 & 110 & 23.3 & \\
\hline \multicolumn{8}{|l|}{ Suicidality $(n=915)$} \\
\hline No & 769 & 84.0 & 396 & 90.4 & 373 & 78.2 & \multirow[t]{2}{*}{$<0.001$} \\
\hline Yes & 146 & 16.0 & 42 & 9.6 & 104 & 21.8 & \\
\hline \multicolumn{8}{|c|}{ Post-traumatic stress disorder (PTSD) $(n=913)$} \\
\hline No & 789 & 86.4 & 407 & 92.9 & 382 & 80.4 & \\
\hline Yes & 124 & 13.6 & 31 & 7.1 & 93 & 19.6 & $<0.001$ \\
\hline \multicolumn{8}{|c|}{ Generalised anxiety disorder $(n=913)$} \\
\hline No & 580 & 63.5 & 292 & 66.5 & 288 & 60.8 & \multirow[t]{2}{*}{0.074} \\
\hline Yes & 333 & 36.5 & 147 & 33.3 & 186 & 39.2 & \\
\hline
\end{tabular}

household, was statistically significant only for GAD (RR $1.65 ; 95 \%$ CI 1.22 to 2.09 ) (not presented in the table). In addition, lack of assets in the household as a proxy for poverty was associated with all mental disorders apart from suicidality in men (table 5 ).

\section{DISCUSSION}

In this study, we found that mental disorders were common among Rwandans aged 20-35, with a higher prevalence in women than men. Traumatic episodes experienced during the genocide period, 17 years prior to this data collection, still strongly contributed to CMDs such as current and past depression, suicidality and GADs, especially in men but also in women. Moreover, traumatic episodes experienced over the lifetime were strongly associated with mental disorders in women. These circumstances indicated that traumatising events also occur in the postgenocide period and influence women's mental health.

Poverty (measured as lack of assets in the household) and lifetime experience of physical/sexual spousal violence were, additionally, strong risk factors in women for the various mental disorders studied. This contributes to explain the generally higher prevalence of all mental disorders in women, that is, women suffered from a multitude of abusive and violent offences including partner violence during and after the genocide period. Poverty constituted a risk factor for mental disorders also in men.

\section{Prevalence of mental disorders in different time periods postgenocide}

A few Rwandan studies exist, and these report on prevalence of mainly PTSD and depression in the aftermath of the genocide in 1994. One study that was conducted 5 years after the genocide included 368 men and women of a mean age of 35.7 years. ${ }^{16}$ The rate of current depression in that study was $11 \%$ in men and $17 \%$ in women, which is somewhat lower than in our study. ${ }^{16}$

Another study investigating the prevalence of PTSD among 2091 people in different provinces 8 years after the genocide found that, on average, $25 \%$ fulfilled the criteria, but data was not sex-disaggregated. ${ }^{22}$ This is somewhat higher than in our study.

Fourteen years after the genocide, a study on PTSD and MDE was conducted on 962 people, aged 1634 years, using the MINI instrument, which was also used in our study. ${ }^{23}$ The prevalence of PTSD in women was $21 \%$ and in men $30 \%$, while MDE in the total sample was $23 \%$. These figures are similar to ours, apart from PTSD in men, which was considerably lower in our study $(7.1 \%)$.

Finally, a study 15 years after the genocide, including 114 survivors of mean age 47 years, reports that $46 \%$ suffered from PTSD, 59\% from anxiety, and another $46 \%$ from current depression. ${ }^{17}$ These figures are considerably higher than in our study for all mental disorders.

These examples illustrate the difficulties encountered when comparing findings from studies conducted with different instruments on differing age and population groups with varying sample sizes. In all cited studies, however, the mental disorders investigated were associated with traumatic episodes experienced during the genocide period. Of note is that a steadily decreasing trend in mental suffering over time was not found as could have been expected due to the elapsed years after the genocide and subsequent repression of memories. However, this could be due to the general approach in Rwanda where people do not forget the genocide or repress memories of what occurred during the 3 months in 1994 and thereafter, in order to avoid reiteration. Every year in April there are commemoration gatherings all over the country, held with the purpose of keeping memories alive and honouring the deceased. 


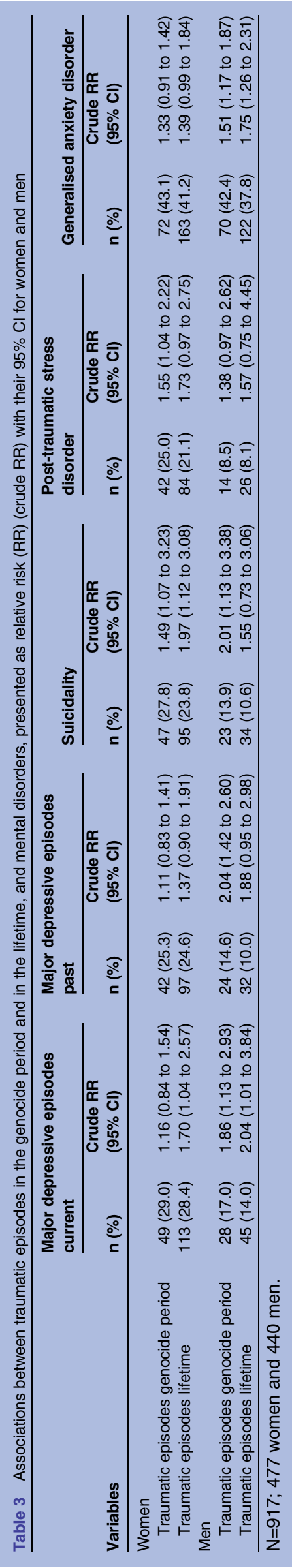

The intergenerational transmission effect

An intergenerational effect is defined by the association between the symptoms of the children of traumatised parents and the parent's own symptoms. ${ }^{36}$ This phenomenon has been explained through several theories, such as the attachment theory (traumatised parents' relative inability to create a secure attachment during the child's early years), and psychosocial stress theory (transmission of stressful social environments due to parental trauma). ${ }^{36}$ It was not possible in this study to present scientific evidence of an intergenerational effect, but it was possible to hypothesise.

The youngest age group (3-5 years) at the time of the genocide), still reported trauma exposure during the genocide period, but whether this was due to what they actually experienced or to what they might have heard from parents, guardians, family members or neighbourhoods, it is difficult to say. The mental health status in this group was no different from what was found for the older ages, and we cannot rule out that this can be ascribed to care givers' relative inability to attach to the young child. The many robust findings of young children at the time of the genocide that still suffer from mental disturbances years after the trauma exposure lend support to such an attachment hypothesis. ${ }^{22} 2338-40$

However, a recent study investigated the mental health status in mothers and their children exposed to trauma during the genocide period in Rwanda, exploring a possible intergenerational effect. ${ }^{20} \mathrm{~A}$ significant relationship between the child's psychopathology and their exposure to maternal violence experienced at home was found, but no clear association with maternal PTSD related to the genocide period. The authors conclude that these findings contradict the common assumption of a direct intergenerational effect. Our findings, however, showed that women's mental health status was influenced by the trauma experienced during the genocide and, as well as by occurrence of spousal violence over the lifetime. Our conclusion is that more studies are needed to establish the links between the generations exposed to trauma and mental disorders, taking exposure to violence into consideration and its possible effects on children.

\section{Risk factors}

Apart from traumatic episodes being associated with mental disorders, poverty was also highly associated with mental disorders for both men and women. Positive associations between a range of poverty indicators and CMDs are found in a systematic review of 115 studies from low income countries. ${ }^{6}$ The main theory regarding the mechanisms of this relationship is the social causation hypothesis, in which conditions of poverty, such as stress, increased negative life events, reduced access to healthcare, and stigma give rise to or maintain mental ill health. ${ }^{6}$ On the other hand, ill health, such as CMDs as a result of a traumatic episode, may lead to difficulties in acquiring education and employment opportunities, in turn leading to poor life circumstances. ${ }^{19}$ 
Table 4 Associations between traumatic episodes experienced over lifetime, and mental disorders for women presented as crude and adjusted relative risk (RR) with their $95 \%$ Cls ( $N=477$ )

\begin{tabular}{|c|c|c|c|c|c|c|c|c|}
\hline & \multicolumn{4}{|c|}{ Major depressive episode current } & \multicolumn{4}{|c|}{ Major depressive episode past } \\
\hline & $\mathrm{n}(\%)$ & Crude & Model $1^{*}$ & Model 2† & n (\%) & Crude & Model 1* & Model 2† \\
\hline \multicolumn{9}{|l|}{ Traumatic episodes lifetime } \\
\hline 0 episode & $13(16.7)$ & 1 & 1 & 1 & $13(16.7)$ & 1 & 1 & 1 \\
\hline$\geq 1$ episodes & $113(28.4)$ & 1.70 (1.04 to 2.57$)$ & $1.74(1.04$ to 2.65$)$ & 1.66 (0.98 to 2.57$)$ & 97 (24.6) & 1.47 (0.88 to 2.29$)$ & $1.52(0.89$ to 2.38$)$ & $1.45(0.84$ to 2.31$)$ \\
\hline \multicolumn{9}{|l|}{ Assets in the household } \\
\hline At least one of the items & $69(20.9)$ & 1 & 1 & 1 & $61(18.7)$ & 1 & 1 & 1 \\
\hline None of the items & 57 (39.0) & 1.87 (1.41 to 2.37 ) & $1.84(1.38$ to 2.35$)$ & 1.70 (1.24 to 2.22$)$ & $49(33.6)$ & 1.80 (1.32 to 2.36$)$ & 1.79 (1.30 to 2.35$)$ & $1.66(1.19$ to 2.23$)$ \\
\hline \multicolumn{9}{|c|}{ Physical/sexual violence exposure lifetime } \\
\hline No & $69(19.7)$ & 1 & & 1 & $63(18.1)$ & 1 & & 1 \\
\hline Yes & $57(45.6)$ & $2.32(1.78$ to 2.87$)$ & - & 2.27 (1.73 to 2.85$)$ & $47(37.6)$ & 2.08 (1.53 to 2.69$)$ & - & 1.91 (1.38 to 2.53$)$ \\
\hline \multirow{3}{*}{$\begin{array}{l}\text { Social support } \\
\text { Good social support } \\
\text { Poor social support }\end{array}$} & & na & na & na & & na & na & na \\
\hline & \multicolumn{4}{|l|}{ Suicidality } & \multicolumn{4}{|c|}{ General anxiety disorder } \\
\hline & $\mathrm{n}(\%)$ & Crude & Model 1* & Model 2† & n (\%) & Crude & Model $1^{*}$ & Model 2† \\
\hline \multicolumn{9}{|l|}{ Traumatic episodes lifetime } \\
\hline 0 episode & $9(11.5)$ & 1 & 1 & 1 & $23(29.5)$ & 1 & 1 & 1 \\
\hline$>1$ episodes & $95(23.8)$ & 2.06 (1.13 to 3.42$)$ & 1.98 (1.08 to 3.30$)$ & 1.91 (1.03 to 3.22$)$ & $163(41.2)$ & 1.39 (0.99 to 1.84$)$ & 1.89 (1.34 to 2.40$)$ & 1.90 (1.34 to 2.42$)$ \\
\hline \multicolumn{9}{|c|}{ (2) } \\
\hline At least one of the items & $66(19.9)$ & 1 & 1 & 1 & $119(36.3)$ & 1 & 1 & 1 \\
\hline None of the items & $38(26.0)$ & $1.31(0.91$ to 1.79$)$ & $1.33(0.93$ to 1.83$)$ & $1.22(0.83$ to 1.71$)$ & $69(45.9)$ & $1.26(1.00$ to 1.54$)$ & $1.20(0.91$ to 1.49$)$ & $1.10(1.82$ to 1.41$)$ \\
\hline \multicolumn{9}{|c|}{ Physical/sexual violence exposure lifetime } \\
\hline No & $62(17.6)$ & 1 & & 1 & $117(33.4)$ & 1 & & 1 \\
\hline Yes & $42(33.6)$ & 1.91 (1.37 to 2.53$)$ & - & $1.86(1.32$ to 2.49$)$ & $69(55.6)$ & 1.67 (1.36 to 1.96$)$ & - & $1.64(1.30$ to 1.97$)$ \\
\hline Social support & & na & na & na & & & & \\
\hline Good social support & & & & & $97(33.4)$ & 1 & 1 & 1 \\
\hline Poor social support & & & & & $70(49.0)$ & 1.46 (1.16 to 1.77$)$ & 1.57 (1.24 to 1.89$)$ & $1.61(1.28$ to 1.94$)$ \\
\hline
\end{tabular}




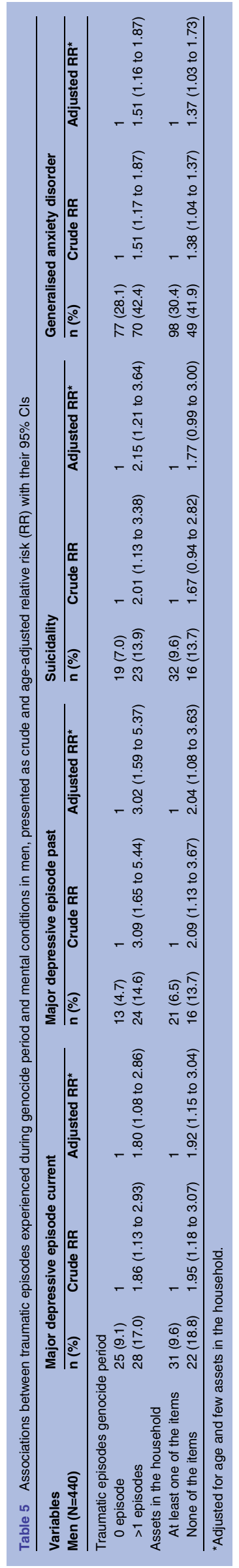

For women, exposure to spousal physical/sexual violence over the lifetime was also highly associated with all mental disorders investigated. There are numerous studies from high and low income countries showing and explaining this association. Also, from Rwanda, it is clearly shown that women suffer from this kind of violence, ${ }^{13}$ and that such experience is linked to CMDs in female victims. ${ }^{42}$ However, one of the findings of interest in this study was that traumatic episodes and physical/sexual violence exposure independently influenced mental health in women.

\section{METHODOLOGICAL CONSIDERATIONS}

The selected age groups for this study included children as young as 3 years of age at the time of the genocide. This may give rise to under-reporting of traumatic exposures especially among the youngest age group. Recall bias, but also memory disturbances and repression, may have caused further under-reporting.

The cross-sectional design allowed for investigating long-term mental health effects of the traumatic episodes during the genocide period as these happened 17 years before the actual data collection. However, these findings are to be interpreted with some caution as this is not a true longitudinal study. The lifetime estimates suffer from an inability to decide on cause and effect due to the cross-sectional design.

The procedure of randomly selecting the participants was done with great care, interviews were conducted by trained clinical psychologists, and the non-response rate was negligible. The data collectors were health workers of similar age as the participants, which has been shown to improve the accuracy of the reporting in interviews. ${ }^{43}$ As Rwanda is a small country with 10 million inhabitants living under rather equal life circumstances, we believe the findings of this study can be generalised to the entire population.

The prevalence of PTSD was not as high in our study as in other postconflict studies from Rwanda. ${ }^{16} 22 \quad 23$ A plausible explanation is that in our study, several mental disorders were included. One of the criticisms of the PTSD diagnosis criteria is its overlap with other mental conditions, and especially with depression. ${ }^{44}$ The use of both depression and PTSD in our study might explain why PTSD was not a prominent outcome in this study. Another criticism is the less stringent diagnostic criteria of PTSD. ${ }^{44}$ The PTSD diagnostic criteria were, however, strengthened in the DSM-V version, while the MINI instrument used in this study is based on the preceding version, that is, on DSM-IV criteria. ${ }^{44}$

Advantages in this study included the use of sexdisaggregated data and the inclusion of spousal physical/sexual violence, which made gender differences evident not only regarding prevalence of mental disorders but also regarding associated factors, where different patterns were seen for men and women, as explained above. 


\section{CONCLUSION}

Depression, PTSD, anxiety and suicidal attempts are prevalent in Rwanda, with rates twice as high in women compared with men. This study shows that exposure to traumatic episodes during the genocide was associated with greater likelihood of mental disorders, especially for men. For women, exposure to physical and sexual abuse was independently associated with all these disorders. Early detection and reduction of gender-based violence through home and community interventions as well as in clinical settings is important. In clinical settings, staff should be aware of the problem, and appropriately trained to care for victims of gender-based violence.

Educational and employment opportunities for both women and men would empower families and communities to ensure a more even distribution of income, reduce poverty and stress in families, whereby also violence against women will be reduced. A mental health literacy campaign should be launched nationwide to reduce the stigma tied to mental disorders, and raise awareness of when and where to seek care.

Acknowledgements The authors wish to recognise the copyright holder of the MINI international neuropsychiatric V.5.0.0 who granted permission to the University of Gothenburg, Department of Public Health and Community Medicine, Sweden, and the University of Rwanda, School of Public Health, Kigali, Rwanda. This study was made possible by a grant from the Swedish International Development cooperation Agency (Sida) and by support from the University of Rwanda, School of Public Health, and the Department of Public Health and Community Medicine, at University of Gothenburg, Sweden. They also thank the data collectors, who sampled the data with great accuracy, and the participants for entrusting us with their information.

Contributors GK designed the project in collaboration with IM and JN. GK, IM and JN developed the questionnaire, and LR complemented it. GK, IM and JN directed all steps of the data collection. LR supervised all the data collection from the field, supervised data entry and cleaning. LR carried out the statistical analyses with support from GK and IM. LR drafted the manuscript, GK, IM and JN read and revised the text. The final version was carefully read and approved by all authors.

Funding This study was supported by a grant from the Swedish International Development Cooperation Agency (Sida) (grant number is SWE 2010-058).

Competing interests None declared.

Ethics approval Permission and ethical clearance was sought from the Rwanda National Ethics Committee. Approval was given with the reference number FWA Assurance No. 00001973, IRB 00001497 of IORG0001100.

Provenance and peer review Not commissioned; externally peer reviewed.

Data sharing statement No additional data are available.

Open Access This is an Open Access article distributed in accordance with the Creative Commons Attribution Non Commercial (CC BY-NC 4.0) license, which permits others to distribute, remix, adapt, build upon this work noncommercially, and license their derivative works on different terms, provided the original work is properly cited and the use is non-commercial. See: http:// creativecommons.org/licenses/by-nc/4.0/

\section{REFERENCES}

1. Levav I, Rutz W. The WHO World Health Report 2001 new understanding-new hope. Isr J Sychiatry Relat Sci 2002;39:50-6.

2. Hock RS, Or F, Kolappa K, et al. A new resolution for global mental health. Lancet 2012;379:1367-8.

3. Saraceno B, van Ommeren M, Batniji R, et al. Barriers to improvement of mental health services in low-income and middle-income countries. Lancet 2007;370:1164-74.
4. WHO. Mental Health Gap Action Programme: Scaling up care for mental, neurological, substance use disorders. 2008. http://www. who.int/mental_health/mhgap/en/

5. WHO. The global burden of disease. 2004. http://www.who.int/ healthinfo/global_burden_disease/2004_report_update/en/ (accessed Oct 2013).

6. Lund C, Breen A, Flisher AJ, et al. Poverty and common mental disorders in low and middle income countries: a systematic review. Soc Sci Med 2010;71:517-28.

7. Devries K, Watts C, Yoshihama M, et al. Violence against women is strongly associated with suicide attempts: evidence from the WHO multi-country study on women's health and domestic violence against women. Soc Sci Med 2011;73:79-86.

8. Leon DA, Walt G. Poverty, inequality and health: an international perspective. Oxford: Oxford University Press, 2001:247-62.

9. WHO. Integrating mental health into primary care-a global perspective. 2008. http://www.who.int/mental_health/policy/services/ integratingmhintoprimarycare/en/

10. Patel V, Araya R, Chatterjee S, et al. Treatment and prevention of mental disorders in low-income and middle-income countries. Lancet 2007:370:991-1005.

11. Patel V. Mental health in low- and middle-income countries. Br Med Bull 2007:81-82:81-96.

12. Truong KD, Ma S. A systematic review of relations between neighborhoods and mental health. J Ment Health Policy Econ 2006;9:137-54.

13. Demographic and Health Survey. National Institute of Statistics of Rwanda. Kigali, Rwanda: Ministry of Health, 2010. http://www. measuredhs.com/pubs/pdf/PR7/PR7.pdf (accessed May 2014)

14. UNFPA. Rwanda: should Rwanda be concerned by the rapid increase of its population? http://rwanda.unfpa.org/2011/08/24/3764/ should_rwanda_be_concerned_by_the_rapid_increase_of_its population/ (accessed Mar 2014).

15. WHO. Rwanda mental health atlas country profile. 2011. Department of Mental Health and Substance Abuse, World Health Organization, 2011. http://www.who.int/mental_health/evidence/ atlas/profiles/rwa mh profile.pdf?ua=1 (accessed May 2014).

16. Bolton P, Neugebauer R, Ndogoni L. Prevalence of depression in rural Rwanda based on symptom and functional criteria. J Nerv Ment Dis 2002;190:631-7.

17. Schaal S, Weierstall R, Dusingizemungu JP. Mental health 15 years after the killings in Rwanda: imprisoned perpetrators of the genocide against the Tutsi versus a community sample of survivors. J Trauma Stress 2012;25:446-53.

18. Neugebauer R, Turner JB, Fisher PW, et al. Posttraumatic stress reactions among Rwandan youth in the second year after the genocide: rising trajectory among girls. Psychol Trauma: Theory Res Pract Policy 2014;6:269-79.

19. Rugema L, Mogren I, Ntaganira J, et al. Traumatic episodes experienced during the genocide period in Rwanda influence life circumstances in young men and women 17 years later. BMC Public Health 2013;13:1235.

20. Roth M, Neuner F, Elbert T. Transgenerational consequences of PTSD: risk factors for the mental health of children whose mothers have been exposed to the Rwandan genocide. Int J Ment Health Syst 2014:8:12.

21. Umubyeyi A, Mogren I, Ntaganira J, et al. Intimate partner violence directed at young men and women in post-genocide Rwanda: Prevalence and risk factors. BMC Womens Health 2014;14:99.

22. Pham PN, Weinstein HM, Longman T. Trauma and PTSD symptoms in Rwanda: implications for attitudes toward justice and reconciliation. JAMA 2004;292:602-12.

23. Munyandamutsa N, Mahoro Nkubamugisha $\mathrm{P}$, Gex-Fabry M, et al. Mental and physical health in Rwanda 14years after the genocide. Soc Psychiatry Psychiatr Epidemiol 2012;47:1753-61.

24. Cohen MH, Fabri M, Cai X, et al. Prevalence and predictors of posttraumatic stress disorder and depression in HIV-infected and at-risk Rwandan women. $J$ Womens Health (Larchmt) 2009;18:1783-91.

25. De Jong J. Public mental health, traumatic stress and human rights violations in low-income countries. In: de Jong J ed. Trauma, war, and violence: public mental health in socio-cultural context. New York: Kluwer Academic/Plenum Publishers, 2002.

26. Ministry of Health. National-Mental-health-Policy in Rwanda. 2005http://www.moh.gov.rw/fileadmin/templates/Docs/ Posted-National-Mental-health-Policy-1.pdf

27. Zraly M, Rubin-Smith J, Betancourt T. Primary mental health care for survivors of collective sexual violence in Rwanda. Global Public Health 2011;6:257-70.

28. Sheehan D, Lecrubier Y, Harnett-Sheehan K, et al. The M.I.N.I. International Neuropsychiatric Interview (M.I.N.I.): the development 
and validation of a structured diagnostic psychiatric interview. $J$ Clin Psychiatry 1998;59(Suppl 20):22-33.

29. Lecrubier $Y$, Sheehan D, Weiller E, et al. The M.I.N.I. International Neuropsychiatric Interview (M.I.N.I.) a short diagnostic structured interview: reliability and validity according to the CIDI. Eur Psychiatry 1997;12:224-31.

30. de Fouchier C, Blanchet A, Hopkins W. Validation of a French adaptation of the Harvard Trauma Questionnaire among torture survivors from sub-Saharan African countries. Eur $J$ Psychotraumatol 2012;10:3402-19225.

31. Oruc L, Kapetanovic A, Pojskic N, et al. Screening for PTSD and depression in Bosnia and Herzegovina: validating the Harvard Trauma Questionnaire and the Hopkins symptom checklist. Int J Cult Ment Health 2008;1:105-16.

32. Mollica R, Caspi-Yavin $Y$, Bollini P. The Harvard Trauma Questionnaire. Validating a cross-cultural instrument for measuring torture, trauma, and posttraumatic stress disorder in Indochinese refugees. J Nerv Ment Dis 1992;180:111-16.

33. Shoeb M, Weinstein H, Mollica R. The Harvard trauma questionnaire: adapting a cross-cultural instrument for measuring torture, trauma and posttraumatic stress disorder in Iraqi refugees. Int J Soc Psychiatry 2007;53:447-63.

34. WHO. Multi-country study on women's Health and Life Experiences. http://www.svri.org/Questionnaire.pdf (accessed May 2014).

35. Zhang J, Yu KF. What's the relative risk? A method of correcting the odds ratio in cohort studies of common outcomes. JAMA 1998;280:1690-1.
36. Daud A, Skoglund E, Rydelius PA. Children in families of torture victims: transgenerational transmission of parents' traumatic experiences to their children. Int J Soc Welf 2005;14:23-32.

37. Devakumar D, Birch M, Osrin D. The intergenerational effects of war on the health of children. BMC Med 2014;12:57.

38. Schaal S, Elbert T. Ten years after the genocide: trauma confrontation and posttraumatic stress in Rwandan adolescents. J Trauma Stress 2006;19:95-105.

39. Schaal S, Jacob N, Dusingizemungu JP. Rates and risks for prolonged grief disorder in a sample of orphaned and widowed genocide survivors. BMC Psychiatry 2010;10:55.

40. Schaal S, Dusingizemungu JP, Jacob N, et al. Rates of trauma spectrum disorders and risks of posttraumatic stress disorder in a sample of orphaned and widowed genocide survivors. Eur $J$ Psychotraumatol. 2011;2:6343.

41. Demographic and Health Survey. National Institute of Statistics of Rwanda. Kigali, Rwanda: Ministry of Health, 2005. http://www. measuredhs.com/publications/ publication-FR183-DHS-Final-Reports.cfm (accessed Apr 2014).

42. Verduin F, Engelhard EA, Rutayisire T. Intimate partner violence in Rwanda: the mental health of victims and perpetrators. J Interpers Violence 2013;28:1839-58.

43. Guest G, Bunce A, Johnson L, et al. Fear, hope and social desirability bias among women at high risk for HIV in West Africa. $J$ Fam Plann Reprod Health Care 2005;31:285-7.

44. Brewin CR, Lanius RA, Novac A. Reformulating PTSD for DSM-V: life after Criterion A. J Trauma Stress 2009;22:366-73. 